\title{
GESTIÓN DE CALIDAD
}

\section{ADOLFO BOUILLON}

Profesor de Gestión de Operaciones

Área Académica de Administración

Facultad de Negocios, UPC

Los procesos claves de negocio de toda organización, cuando son adecuadamente gestionados, permiten entregar productos o servicios de valor a los clientes. La productividad es un concepto utilizado para medir la ejecución de un proceso u operación, y lo importante es que se puede aplicar tanto a productos como a servicios. En este último caso, suele ser un poco más difícil establecer medidas cuantitativas de desempeño. Esto se debe a que los servicios, por naturaleza, implican una alta interacción con los clientes, por lo que se pueden esperar comportamientos que no necesariamente siguen un mismo patrón. Aun así, existen modelos que permiten realizar adecuadamente estimaciones de desempeño.

La gestión de la calidad debe ser una filosofía de trabajo más que una serie de procedimientos para mantener una determinada certificación (e.g., ISO 9000), a pesar que existe una correlación positiva entre la cantidad de empresas certificadas y algunos indicadores macroeconómicos (Salgado, Beijo, Sampaio, Mello, \& Saraiva, 2016). Esta filosofía supone un cambio de paradigma, desde la perspectiva dependiente hacia la interdependiente, en la cual los trabajadores asumen como suya la responsabilidad de velar por que los procesos se efectúen en forma adecuada, es decir a través de una motivación intrínseca, de manera que la experiencia del cliente con el servicio sea la mejor (Psomas \& Antony, 2015).

En el mes de mayo del presente año, la empresa British Airways tuvo que cancelar todas sus operaciones de vuelo debido a un error en su sistema informático. Esta situación generó molestias en los pasajeros en varias terminales aéreas a lo largo de Europa. En una empresa de aviación comercial la experiencia del cliente está relacionada con los resultados del viaje. Hay elementos internos tras bambalinas que no representan mayor interés para los clientes, pero que tienen un gran impacto. En ese sentido, los sistemas de información gerencial (MIS) desempeñan un rol muy importante, pues la información de los vuelos - es decir, despegues y aterrizajes - brinda la orientación y la oportunidad para que los pasajeros puedan planificar adecuadamente sus tiempos. Las fallas en los sistemas de información generaron la cancelación de vuelos de British Airways, hecho que de por sí ocasiona problemas con las actividades de los pasajeros, pues ellos esperan poder realizar sus viajes en las fechas que han programado.

Asimismo, los pocos que sí pudieron viajar debieron hacerlo sin equipaje, con lo que se originó una nueva incomodidad. Esta situación también produjo malestar en la terminal aérea, pues la falta de información deriva en aglomeración de clientes, quienes desean saber los estados de sus vuelos.

Al hablar de gestión de la calidad, se tienen dos grandes tipos de costos: costos de control y costos de fallas. Los primeros hacen alusión a los costos involucrados con la prevención y la evaluación de los diferentes subsistemas de la empresa; los segundos se refieren a las fallas internas y externas de la organización y se dan después de ocurrido el problema, luego de que el error se haya manifestado--en este caso, la falla informática. Los costos de fallas representan, entre otros, los gastos en alojamiento, alimentación y traslado de pasajeros, y suelen ser mucho más onerosos de lo que se estima inicialmente, sobre todo si existen costos intangibles, como la pérdida de credibilidad o la no recomendación de un servicio, lo que hace perder muchas ventas potenciales a futuro. 
Tomar conciencia de estos costos permitirá realizar prácticas de gestión de calidad en las empresas, pero adicionalmente se debe considerar que más importante aún es la generación de capacidades, que posibilita la incorporación de la filosofía de control de calidad para las empresas (Camisón, \& Puig-Denia, 2016). Por ello, el manejo de situaciones como estas es crítico para el buen desempeño de la organización.

En el mes de junio, Indecopi abrió un proceso disciplinario contra la empresa Viva Air debido a la cancelación y reprogramación de vuelos en varias fechas, lo que ocasionó incomodidad entre los pasajeros, que debieron cambiar sus horarios de vuelo. Adicionalmente, en caso de que no haya disponibilidad de vuelos en la nueva fecha que el cliente elija, la empresa aplica un cargo adicional, lo cual puede ahondar más en el descontento por el desempeño del servicio ofrecido.

Si opina que los esfuerzos y las inversiones de la calidad no justifican los resultados obtenidos, piense en lo siguiente: de acuerdo con expertos en aviación comercial, se afirma que la reprogramación de vuelos de British Airways, por el problema antes identificado, le costará a la empresa alrededor de 180 millones de euros. No es una cantidad menor. El esfuerzo para controlar adecuadamente la calidad en los procesos de negocio puede significar grandes ahorros para la organización.

La solución empieza por realizar un diagnóstico de los procesos de la compañía, de modo que se identifiquen cuellos de botella; bajos rendimientos; y posibles fallas futuras. En este esfuerzo, pueden utilizarse técnicas estadísticas de control de calidad. Una vez identificadas las fallas, podría ser adecuado aplicar técnicas matemáticas de optimización (e.g., la programación lineal), con el fin de optimizar la asignación de recursos. Otra técnica importante es la simulación de sistemas, para probar el desempeño de un sistema de operaciones en un entorno simulado y, de esta forma, entenderlo cabalmente y proponer soluciones adecuadas en beneficio de los clientes, para quienes nunca será suficiente cualquier esfuerzo de la empresa por mejorar su experiencia de compra. Sólo así se entrará en el círculo virtuoso de crecimiento y desarrollo organizacional, sin "turbulencias" de ninguna clase.

\section{Referencias}

Camisón, C., \& Puig-Denia, A. (2016). Are quality management practices enough to improve process innovation? International Journal of Production Research, 54(10), 2875-2894

Psomas, E., \& Antony, J. (2015). The effectiveness of the ISO 9001 quality management system and its influential critical factors in Greek manufacturing companies. International Journal of Production Research, 53(7), 2089-2099.

Salgado, E. G., Beijo, L. A., Sampaio, P., Mello, C. H. P., \& Saraiva, P. (2016). ISO 9001 certification in the American Continent: a statistical analysis and modelling. International Journal of Production Research, 54(18), 5416-5433. 